\title{
Adaptive e-learning environment based on learning styles and its impact on development students' engagement
}

\author{
Hassan A. El-Sabagh ${ }^{1,2^{*}}$ (1)
}

\author{
${ }^{*}$ Correspondence: \\ haelsabagh@uqu.edu.sa; \\ haelsabagh@mans.edu.eg \\ ${ }^{1}$ E-Learning Deanship, Umm \\ Al-Qura University, Mecca, \\ Saudi Arabia \\ Full list of author information \\ is available at the end of the \\ article
}

\begin{abstract}
Adaptive e-learning is viewed as stimulation to support learning and improve student engagement, so designing appropriate adaptive e-learning environments contributes to personalizing instruction to reinforce learning outcomes. The purpose of this paper is to design an adaptive e-learning environment based on students' learning styles and study the impact of the adaptive e-learning environment on students' engagement. This research attempts as well to outline and compare the proposed adaptive e-learning environment with a conventional e-learning approach. The paper is based on mixed research methods that were used to study the impact as follows: Development method is used in designing the adaptive e-learning environment, a quasi-experimental research design for conducting the research experiment. The student engagement scale is used to measure the following affective and behavioral factors of engagement (skills, participation/interaction, performance, emotional). The results revealed that the experimental group is statistically significantly higher than those in the control group. These experimental results imply the potential of an adaptive e-learning environment to engage students towards learning. Several practical recommendations forward from this paper: how to design a base for adaptive e-learning based on the learning styles and their implementation; how to increase the impact of adaptive e-learning in education; how to raise cost efficiency of education. The proposed adaptive e-learning approach and the results can help e-learning institutes in designing and developing more customized and adaptive e-learning environments to reinforce student engagement.
\end{abstract}

Keywords: Adaptive e-Learning, Learning style, Student engagement, E-Learning, Learning impact

\section{Introduction}

In recent years, educational technology has advanced at a rapid rate. Once learning experiences are customized, e-learning content becomes richer and more diverse (ElSabagh \& Hamed, 2020; Yang et al., 2013). E-learning produces constructive learning outcomes, as it allows students to actively participate in learning at anytime and anyplace (Chen et al., 2010; Lee et al., 2019). Recently, adaptive e-learning has become an approach that is widely implemented by higher education institutions. The adaptive

(c) The Author(s), 2021. Open Access This article is licensed under a Creative Commons Attribution 4.0 International License, which permits use, sharing, adaptation, distribution and reproduction in any medium or format, as long as you give appropriate credit to the original author(s) and the source, provide a link to the Creative Commons licence, and indicate if changes were made. The images or other third party material in this article are included in the article's Creative Commons licence, unless indicated otherwise in a credit line to the material. If material is not included in the article's Creative Commons licence and your intended use is not permitted by statutory regulation or exceeds the permitted use, you will need to obtain permission directly from the copyright holder. To view a copy of this licence, visit http:// creativecommons.org/licenses/by/4.0/. 
e-learning environment (ALE) is an emerging research field that deals with the development approach to fulfill students' learning styles by adapting the learning environment within the learning management system "LMS" to change the concept of delivering e-content. Adaptive e-learning is a learning process in which the content is taught or adapted based on the responses of the students' learning styles or preferences. (Normadhi et al., 2019; Oxman \& Wong, 2014). By offering customized content, adaptive e-learning environments improve the quality of online learning. The customized environment should be adaptable based on the needs and learning styles of each student in the same course. (Franzoni \& Assar, 2009; Kolekar et al., 2017). Adaptive e-learning changes the level of instruction dynamically based on student learning styles and personalizes instruction to enhance or accelerate a student's success. Directing instruction to each student's strengths and content needs can minimize course dropout rates, increase student outcomes and the speed at which they are accomplished. The personalized learning approach focuses on providing an effective, customized, and efficient path of learning so that every student can participate in the learning process (Hussein \& Al-Chalabi, 2020). Learning styles, on the other hand, represent an important issue in learning in the twenty-first century, with students expected to participate actively in developing self-understanding as well as their environment engagement. (KlasnjaMilicevic et al., 2011; Nuankaew et al., 2019; Truong, 2016).

In current conventional e-learning environments, instruction has traditionally followed a "one style fits all" approach, which means that all students are exposed to the same learning procedures. This type of learning does not take into account the different learning styles and preferences of students. Currently, the development of e-learning systems has accommodated and supported personalized learning, in which instruction is fitted to a students' individual needs and learning styles (Beldagli \& Adiguzel, 2010; Benhamdi et al., 2017; Pashler et al., 2008). Some personalized approaches let students choose content that matches their personality (Hussein \& Al-Chalabi, 2020). The delivery of course materials is an important issue of personalized learning. Moreover, designing a well-designed, effective, adaptive e-learning system represents a challenge due to complication of adapting to the different needs of learners (Alshammari, 2016). Regardless of using e-learning claims that shifting to adaptive e-learning environments to be able to reinforce students' engagement. However, a learning environment cannot be considered adaptive if it is not flexible enough to accommodate students' learning styles. (Ennouamani \& Mahani, 2017).

On the other hand, while student engagement has become a central issue in learning, it is also an indicator of educational quality and whether active learning occurs in classes. (Lee et al., 2019; Nkomo et al., 2021; Robinson \& Hullinger, 2008). Veiga et al. (2014) suggest that there is a need for further research in engagement because assessing students' engagement is a predictor of learning and academic progress. It is important to clarify the distinction between causal factors such as learning environment and outcome factors such as achievement. Accordingly, student engagement is an important research topic because it affects a student's final grade, and course dropout rate (Staikopoulos et al., 2015).

The Umm Al-Qura University strategic plan through common first-year deanship has focused on best practices that increase students' higher-order skills. These skills 
include communication skills, problem-solving skills, research skills, and creative thinking skills. Although the UQU action plan involves improving these skills through common first-year academic programs, the student's learning skills need to be encouraged and engaged more (Umm Al-Qura University Agency, 2020). As a result of the author's experience, The conventional methods of instruction in the "learning skills" course were observed, in which the content is presented to all students in one style that is dependent on understanding the content regardless of the diversity of their learning styles.

According to some studies (Alshammari \& Qtaish, 2019; Lee \& Kim, 2012; Shih et al., 2008; Verdú, et al., 2008; Yalcinalp \& Avc, 2019), there is little attention paid to the needs and preferences of individual learners, and as a result, all learners are treated in the same way. More research into the impact of educational technologies on developing skills and performance among different learners is recommended. This "one-style-fitsall" approach implies that all learners are expected to use the same learning style as prescribed by the e-learning environment. Subsequently, a review of the literature revealed that an adaptive e-learning environment can affect learning outcomes to fill the identified gap. In conclusion: Adaptive e-learning environments rely on the learner's preferences and learning style as a reference that supports to create adaptation.

To confirm the above: the author conducted an exploratory study via an open interview that included some questions with a sample of 50 students in the learning skills department of common first-year. Questions asked about the difficulties they face when learning a "learning skills" course, what is the preferred way of course content. Students $(88 \%)$ agreed that the way students are presented does not differ according to their differences and that they suffer from a lack of personal learning that is compatible with their style of work. Students (82\%) agreed that they lack adaptive educational content that helps them to be engaged in the learning process. Accordingly, the author handled the research problem.

This research supplements to the existing body of knowledge on the subject. It is considered significant because it improves understanding challenges involved in designing the adaptive environments based on learning styles parameter. Subsequently, this paper is structured as follows: The next section presents the related work cited in the literature, followed by research methodology, then data collection, results, discussion, and finally, some conclusions and future trends are discussed.

\section{Theoretical framework}

This section briefly provides a thorough review of the literature about the adaptive E-learning environments based on learning styles.

\section{Adaptive e-learning environments based on learning styles}

The adaptive e-learning employment in higher education has been slower to evolve, and challenges that led to the slow implementation still exist. The learning management system offers the same tools to all learners, although individual learners need different details based on learning style and preferences. (Beldagli \& Adiguzel, 2010; Kolekar et al., 2017). The interactive e-learning environment requisite evaluating the learner's desired learning style, before the course delivery, such as an online quiz or during the course delivery, such as tracking student reactions (DeCapua \& Marshall, 2015). 
In e-learning environments, adaptation is constructed on a series of well-designed processes to fit the instructional materials. The adaptive e-learning framework attempt to match instructional content to the learners' needs and styles. According to Qazdar et al. (2015), adaptive e-learning (AEL) environments rely on constructing a model of each learner's needs, preferences, and styles. It is well recognized that such adaptive behavior can increase learners' development and performance, thus enriching learning experience quality. (Shi et al., 2013). The following features of adaptive e-learning environments can be identified through diversity, interactivity, adaptability, feedback, performance, and predictability. Although adaptive framework taxonomy and characteristics related to various elements, adaptive learning includes at least three elements: a model of the structure of the content to be learned with detailed learning outcomes (a content model). The student's expertise based on success, as well as a method of interpreting student strengths (a learner model), and a method of matching the instructional materials and how it is delivered in a customized way (an instructional model) (Ali et al., 2019). The number of adaptive e-learning studies has increased over the last few years. Adaptive e-learning is likely to increase at an accelerating pace at all levels of instruction (Hussein \& Al-Chalabi, 2020; Oxman \& Wong, 2014).

Many studies assured the power of adaptive e-learning in delivering e-content for learners in a way that fitting their needs, and learning styles, which helps improve the process of students' acquisition of knowledge, experiences and develop their higher thinking skills (Ali et al., 2019; Behaz \& Djoudi, 2012; Chun-Hui et al., 2017; Daines et al., 2016; Dominic et al., 2015; Mahnane et al., 2013; Vassileva, 2012). Student characteristics of learning style are recognized as an important issue and a vital influence in learning and are frequently used as a foundation to generate personalized learning experiences (Alshammari \& Qtaish, 2019; El-Sabagh \& Hamed, 2020; Hussein \& Al-Chalabi, 2020; Klasnja-Milicevic et al., 2011; Normadhi et al., 2019; Ozyurt \& Ozyurt, 2015).

The learning style is a parameter of designing adaptive e-learning environments. Individuals differ in their learning styles when interacting with the content presented to them, as many studies emphasized the relationship between e-learning and learning styles to be motivated in learning situations, consequently improving the learning outcomes (Ali et al., 2019; Alshammari, 2016; Alzain et al., 2018a, b; Liang, 2012; Mahnane et al., 2013; Nainie et al., 2010; Velázquez \& Assar, 2009). The word "learning style" refers to the process by which the learner organizes, processes, represents, and combines this information and stores it in his cognitive source, then retrieves the information and experiences in the style that reflects his technique of communicating them. (Fleming \& Baume, 2006; Jaleel \& Thomas, 2019; Jonassen \& Grabowski, 2012; Klasnja-Milicevic et al., 2011; Nuankaew et al., 2019; Pashler et al., 2008; Willingham et al., 2105; Zhang, 2017). The concept of learning style is founded based on the fact that students vary in their styles of receiving knowledge and thought, to help them recognizing and combining information in their mind, as well as acquire experiences and skills. (Naqeeb, 2011). The extensive scholarly literature on learning styles is distributed with few strong experimental findings (Truong, 2016), and a few findings on the effect of adapting instruction to learning style. There are many models of learning styles (Aldosarim et al., 2018; Alzain et al., 2018a, 2018b; Cletus \& Eneluwe, 2020; Franzoni \& Assar, 2009; Willingham et al., 2015), including the VARK model, which is one of the most well-known models used to 
classify learning styles. The VARK questionnaire offers better thought about information processing preferences (Johnson, 2009). Fleming and Baume (2006) developed the VARK model, which consists of four students' preferred learning types. The letter "V" represents for visual and means the visual style, while the letter "A" represents for auditory and means the auditory style, and the letter "R/W" represents "write/read", means the reading/writing style, and the letter "K" represents the word "Kinesthetic" and means the practical style. Moreover, VARK distinguishes the visual category further into graphical and textual or visual and read/write learners (Murphy et al., 2004; Leung, et al., 2014; Willingham et al., 2015). The four categories of The VARK Learning Style Inventory are shown in the Fig. 1 below.

According to the VARK model, learners are classified into four groups representing basic learning styles based on their responses which have 16 questions, there are four potential responses to each question, where each answer agrees to one of the extremes of the dimension (Hussain, 2017; Silva, 2020; Zhang, 2017) to support instructors who use it to create effective courses for students. Visual learners prefer to take instructional materials and send assignments using tools such as maps, graphs, images, and other symbols, according to Fleming and Baume (2006). Learners who can read-write prefer to use written textual learning materials, they use glossaries, handouts, textbooks, and lecture notes. Aural learners, on the other hand, prefer to learn through spoken materials, dialogue, lectures, and discussions. Direct practice and learning by doing are preferred by kinesthetic learners (Becker et al., 2007; Fleming \& Baume, 2006; Willingham et al., 2015). As a result, this research work aims to provide a comprehensive discussion about how these individual parameters can be applied in adaptive e-learning environment practices. Dominic et al., (2015) presented a framework for an adaptive educational system that personalized learning content based on student learning styles (Felder-Silverman learning model) and other factors such as learners' learning subject competency level. This framework allowed students to follow their adaptive learning content paths based on filling in "ils" questionnaire. Additionally, providing a customized framework that can automatically respond to students' learning styles and suggest online activities with complete personalization. Similarly, El Bachari et al. (2011) attempted to determine a student's unique learning style and then adapt instruction to that individual interests. Adaptive e-learning focused on learner experience and learning style has a higher degree

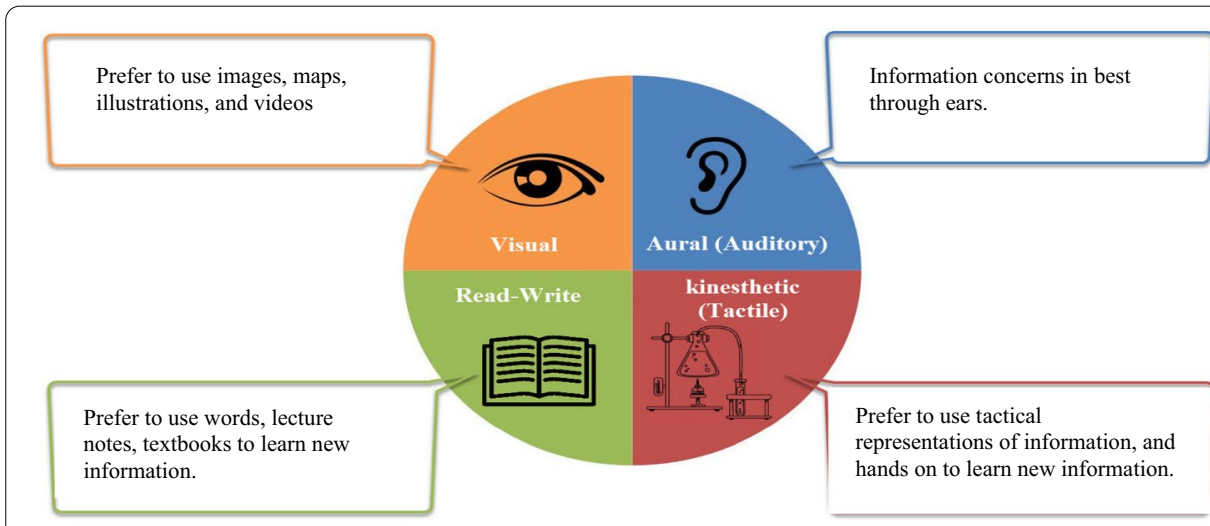

Fig. 1 VARK learning styles 
of perceived usability than a non-adaptive e-learning system, according to Alshammari et al. (2015). This can also improve learners' satisfaction, engagement, and motivation, thus improving their learning.

According to the findings of (Akbulut \& Cardak, 2012; Alshammari \& Qtaish, 2019; Alzain et al., 2018a, b; Shi et al., 2013; Truong, 2016), adaptation based on a combination of learning style, and information level yields significantly better learning gains. Researchers have recently initiated to focus on how to personalize e-learning experiences using personal characteristics such as the student's preferred learning style. Personal learning challenges are addressed by adaptive learning programs, which provide learners with courses that are fit to their specific needs, such as their learning styles.

\section{Student engagement}

Previous research has emphasized that student participation is a key factor in overcoming academic problems such as poor academic performance, isolation, and high dropout rates (Fredricks et al., 2004). Student participation is vital to student learning, especially in an online environment where students may feel isolated and disconnected (Dixson, 2015). Student engagement is the degree to which students consciously engage with a course's materials, other students, and the instructor. Student engagement is significant for keeping students engaged in the course and, as a result, in their learning (Barkley \& Major, 2020; Lee et al., 2019; Rogers-Stacy, et al, 2017). Extensive research was conducted to investigate the degree of student engagement in web-based learning systems and traditional education systems. For instance, using a variety of methods and input features to test the relationship between student data and student participation (Hussain et al., 2018). Guo et al. (2014) checked the participation of students when they watched videos. The input characteristics of the study were based on the time they watched it and how often students respond to the assessment.

Atherton et al. (2017) found a correlation between the use of course materials and student performance; course content is more expected to lead to better grades. Pardo et al., (2016) found that interactive students with interactive learning activities have a significant impact on student test scores. The course results are positively correlated with student participation according to previous research. For example, Atherton et al. (2017) explained that students accessed learning materials online and passed exams regularly to obtain higher test scores. Other studies have shown that students with higher levels of participation in questionnaires and course performance tend to perform well (Mutahi et al., 2017).

Skills, emotion, participation, and performance, according to Dixson (2015), were factors in online learning engagement. Skills are a type of learning that includes things like practicing on a daily foundation, paying attention while listening and reading, and taking notes. Emotion refers to how the learner feels about learning, such as how much you want to learn. Participation refers to how the learner act in a class, such as chat, discussion, or conversation. Performance is a result, such as a good grade or a good test score. In general, engagement indicated that students spend time, energy learning materials, and skills to interact constructively with others in the classroom, and at least participate in emotional learning in one way or another (that is, be motivated by an idea, willing to learn and interact). Student engagement is produced through personal attitudes, 
thoughts, behaviors, and communication with others. Thoughts, effort, and feelings to a certain level when studying. Therefore, the student engagement scale attempts to measure what students are doing (thinking actively), how they relate to their learning, and how they relate to content, faculty members, and other learners including the following factors as shown in Fig. 2. (skills, participation/interaction, performance, and emotions). Hence, previous research has moved beyond comparing online and face-to-face classes to investigating ways to improve online learning (Dixson, 2015; Gaytan \& McEwen, 2007; Lévy \& Wakabayashi, 2008; Mutahi et al., 2017). Learning effort, involvement in activities, interaction, and learning satisfaction, according to reviews of previous research on student engagement, are significant measures of student engagement in learning environments (Dixson, 2015; Evans et al., 2017; Lee et al., 2019; Mutahi et al., 2017; RogersStacy et al., 2017). These results point to several features of e-learning environments that can be used as measures of student participation. Successful and engaged online learners learn actively, have the psychological inspiration to learn, make good use of prior experience, and make successful use of online technology. Furthermore, they have excellent communication abilities and are adept at both cooperative and self-directed learning (Dixson, 2015; Hong, 2009; Nkomo et al., 2021).

\section{Overview of designing the adaptive e-learning environment}

The paper follows the (ADDIE) Instructional Design Model: analysis, design, develop, implement, and evaluate to answer the first research question. The adaptive learning environment offers an interactive decentralized media environment that takes into account individual differences among students. Moreover, the environment can spread the culture of self-learning, attract students, and increase their engagement in learning.

Any learning environment that is intended to accomplish a specific goal should be consistent to increase students' motivation to learn. so that they have content that is personalized to their specific requirements, rather than one-size-fits-all content. As a result, a set of instructional design standards for designing an adaptive e-learning framework based on learning styles was developed according to the following diagram (Fig. 3).

According to the previous figure, The analysis phase included identifying the course materials and learning tools (syllabus and course plan modules) used for the study. The learning objectives were included in the high-level learning objectives (C4-C6: analysis, synthesis, evaluation).

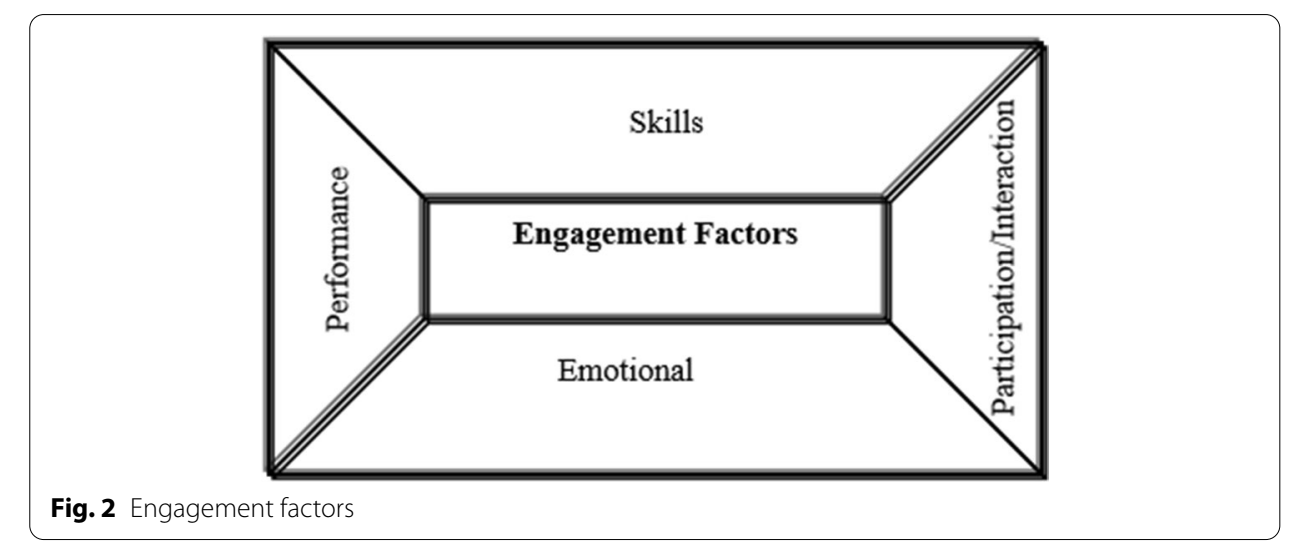




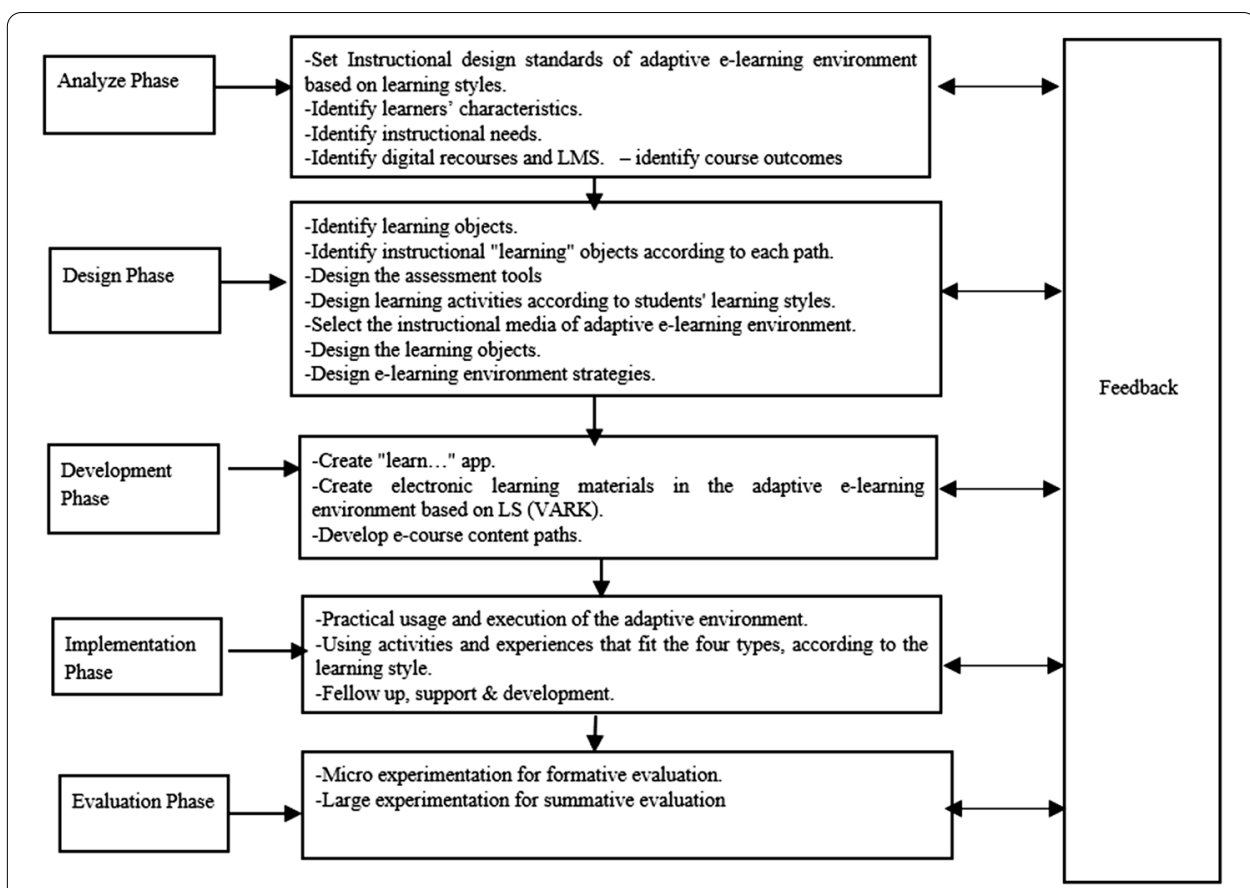

Fig. 3 The ID (model) of the adaptive e-learning environment

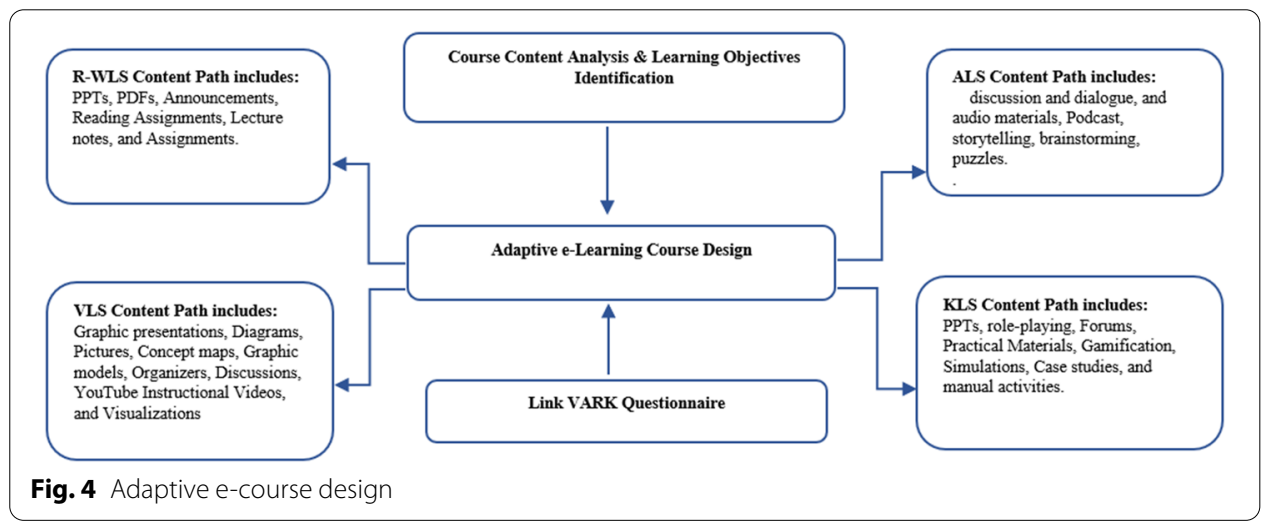

The design phase included writing SMART objectives, the learning materials were written within the modules plan. To support adaptive learning, four content paths were identified, choosing learning models, processes, and evaluation. Course structure and navigation were planned. The adaptive structural design identified the relationships between the different components, such as introduction units, learning materials, quizzes. Determining the four path materials. The course instructional materials were identified according to the following Figure 4.

The development phase included: preparing and selecting the media for the e-course according to each content path in an adaptive e-learning environment. During this process, the author accomplished the storyboard and the media to be included on 
each page of the storyboard. A category was developed for the instructional media for each path (Fig. 5)

The author developed a learning styles questionnaire via a mobile App. as follows: https://play.google.com/store/apps/details?id=com.pointability.vark. Then, the students accessed the adaptive e-course modules based on their learning styles.

The Implementation phase involved the following: The professional validation of the course instructional materials. Expert validation is used to evaluate the consistency of course materials (syllabi and modules). The validation was performed including the following: student learning activities, learning implementation capability, and student reactions to modules. The learner's behaviors, errors, navigation, and learning process are continuously geared toward improving the learner's modules based on the data the learner gathered about him.

The Evaluation phase included five e-learning specialists who reviewed the adaptive e-learning. After that, the framework was revised based on expert recommendations and feedback. Content assessment, media evaluation in three forms, instructional design, interface design, and usage design included in the evaluation. Adaptive learners checked the proposed framework. It was divided into two sections. Pilot testing where the proposed environment was tested by ten learners who represented the sample in the first phase. Each learner's behavior was observed, questions were answered, and learning control, media access, and time spent learning were all verified.

\section{Research methodology}

\section{Research Purpose and Questions}

This research aims to investigate the impact of designing an adaptive e-learning environment on the development of students' engagement. The research conceptual framework is illustrated in Fig. 6. Therefore, the articulated research questions are as follows: the main research question is "What is the impact of an adaptive e-learning environment based on (VARK) learning styles on developing students' engagement?

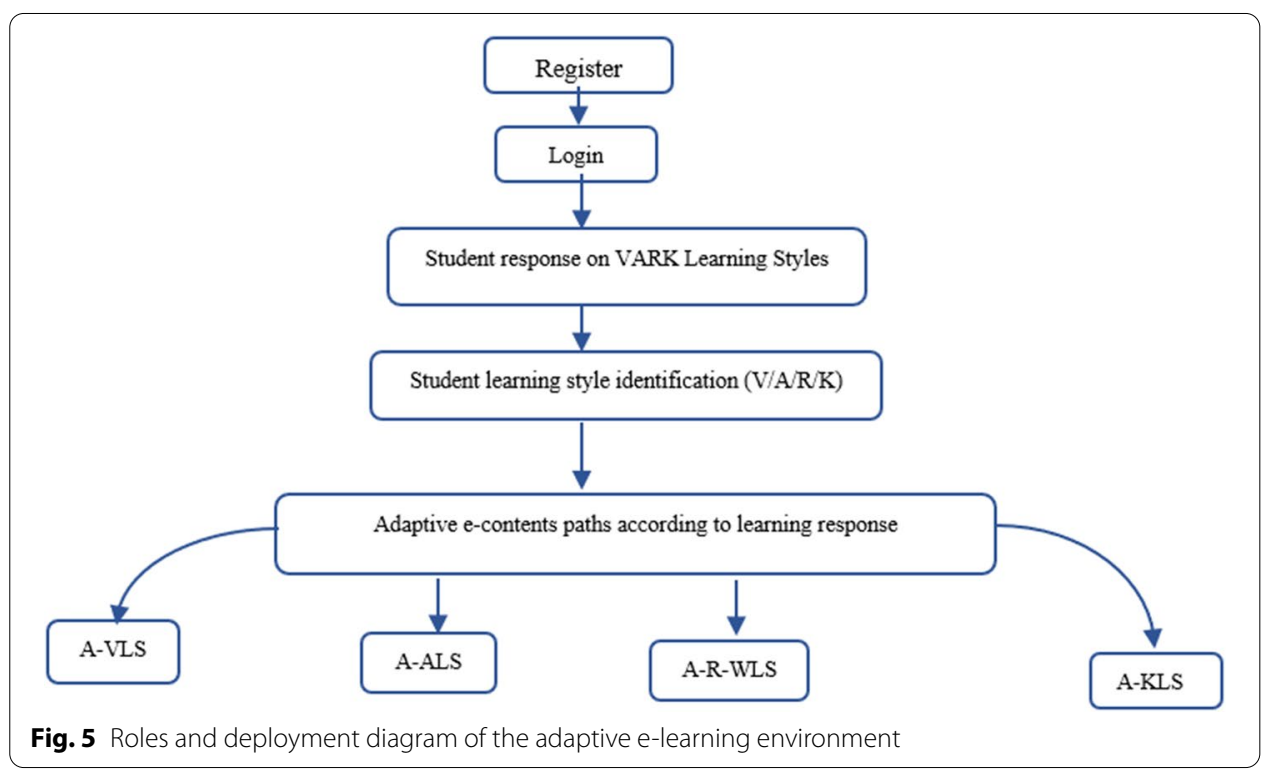




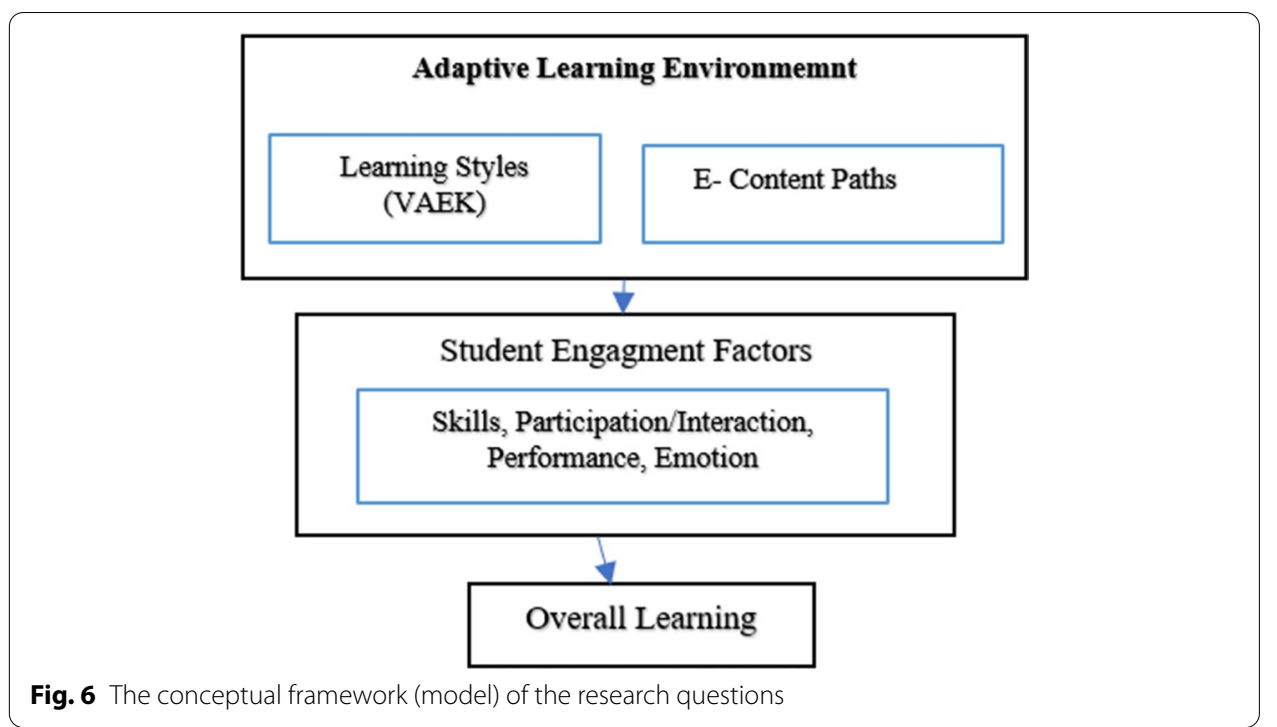

Accordingly, there are two sub research questions a) "What is the instructional design of the adaptive e-learning environment?" b) "What is the impact of an adaptive e-learning based on (VARK) learning styles on development students' engagement (skills, participation, performance, emotional) in comparison with conventional e-learning?".

\section{Research hypotheses}

The research aims to verify the validity of the following hypothesis:

H1: There is no statistically significant difference between the students' mean scores of the experimental group that exposed to the adaptive e-learning environment and the scores of the control group that was exposed to the conventional e-learning environment in pre-application of students' engagement scale.

H2: There is a statistically significant difference at the level of $(0.05)$ between the students' mean scores of the experimental group (adaptive e-learning) and the scores of the control group (conventional e-learning) in post-application of students' engagement factors in favor of the experimental group.

\section{Research design}

This research was a quasi-experimental research with the pretest-posttest. Research variables were independent and dependent as shown in the following Fig. 7.

Both groups were informed with the learning activities tracks, the experimental group was instructed to use the adaptive learning environment to accomplish the learning goals; on the other hand, the control group was exposed to the conventional e-learning environment without the adaptive e-learning parameters. 


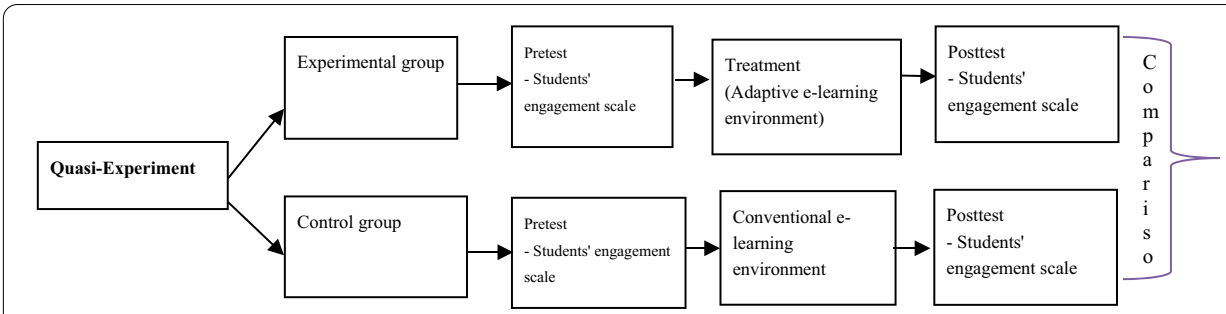

Fig. 7 Research "Experimental" design

Table 1 Students' demographic data

\begin{tabular}{llll}
\hline Age & Gender & Total \\
\cline { 2 - 3 } & M & F & \\
\hline Experimental students & 36 & 24 & 60 \\
Control group & 31 & 27 & 58 \\
\hline
\end{tabular}

\section{Research participants}

The sample consisted of students studying the "learning skills" course in the common first-year deanship aged between (17-18) years represented the population of the study. All participants were chosen in the academic year 2109-2020 at the first term which was taught by the same instructors. The research sample included two classes (118 students), selected randomly from the learning skills department. First-group was randomly assigned as the control group $(\mathrm{N}=58,31$ males and 27 females), the other was assigned as experimental group ( $\mathrm{N}=60,36$ males and 24 females) was assigned to the other class. The following Table 1 shows the distribution of students' sample "Demographics data".

The instructional materials were not presented to the students before. The control group was expected to attend the conventional e-learning class, where they were provided with the learning environment without adaptive e-learning parameter based on the learning styles that introduced the "learning skills" course. The experimental group was exposed to the use of adaptive e-learning based on learning styles to learn the same course instructional materials within e-course. Moreover, all the student participants were required to read the guidelines to indicate their readiness to participate in the research experiment with permission.

\section{Research instruments}

In this research, the measuring tools included the VARK questionnaire and the students' engagement scale including the following factors (skills, participation/interaction, performance, emotional). To begin, the pre-post scale was designed to assess the level of student engagement related to the "learning skills" course before and after participating in the experiment.

\section{VARK questionnaire}

Questionnaires are a common method for collecting data in education research (McMillan \& Schumacher, 2006). The VARK questionnaire had been organized electronically 
and distributed to the student through the developed mobile app and registered on the UQU system. The questionnaire consisted of 16 items within the scale as MCQ classified into four main factors (kinesthetic, auditory, visual, and R/W).

Reliability and Validity of The VARK questionnaire For reliability analysis, Cronbach's alpha is used for evaluating research internal consistency. Internal consistency was calculated through the calculation of correlation of each item with the factor to which it fits and correlation among other factors. The value of 0.70 and above are normally recognized as high-reliability values (Hinton et al., 2014). The Cronbach's Alpha correlation coefficient for the VARK questionnaire was 0.83 , indicating that the questionnaire was accurate and suitable for further research.

\section{Students' engagement scale}

The engagement scale was developed after a review of the literature on the topic of student engagement. The Dixson scale was used to measure student engagement. The scale consisted of 4 major factors as follows (skills, participation/interaction, performance, emotional). The author adapted the original "Dixson scale" according to the following steps. The Dixson scale consisted of 48 statements was translated and accommodated into Arabic by the author. After consulting with experts, the instrument items were reduced to 27 items after adaptation according to the university learning environment. The scale is rated on a 5-point scale.

The final version of the engagement scale comprised 4 factors as follows: The skills engagement included (ten items) to determine keeping up with, reading instructional materials, and exerting effort. Participation/interaction engagement involved (five items) to measure having fun, as well as regularly engaging in group discussion. The performance engagement included (five items) to measure test performance and receiving a successful score. The emotional engagement involved (seven items) to decide whether or not the course was interesting. Students can access to respond engagement scale from the following link: http://bit.ly/2PXGvvD. Consequently, the objective of the scale is to measure the possession of common first-year students of the basic engagement factors before and after instruction with adaptive e-learning compared to conventional e-learning.

Reliability and validity of the engagement scale The alpha coefficient of the scale factors scores was presented. All four subscales have a strong degree of internal accuracy $(0.80-$ $0.87)$, indicating strong reliability. The overall reliability of the instruments used in this study was calculated using Alfa-alpha, Cronbach's with an alpha value of 0.81 meaning that the instruments were accurate. The instruments used in this research demonstrated strong validity and reliability, allowing for an accurate assessment of students' engagement in learning. The scale was applied to a pilot sample of 20 students, not including the experimental sample. The instrument, on the other hand, had a correlation coefficient of (0.74-0.82), indicating a degree of validity that enables the instrument's use. Table 2 shows the correlation coefficient and Cronbach's alpha based on the interaction scale.

On the other hand, to verify the content validity; the scale was to specialists to take their views on the clarity of the linguistic formulation and its suitability to 
Table 2 Correlation coefficient and Cronbach's Alpha of engagement scale

\begin{tabular}{lll}
\hline Students' engagement factors & Validity Pearson Correlation & $\begin{array}{l}\text { Reliability } \\
\text { Alpha } \\
\text { Cronbach }\end{array}$ \\
\hline Skills & & 0.80 \\
Participation/interaction & 0.70 & 0.84 \\
Performance & 0.82 & 0.87 \\
Emotional & 0.78 & 0.83 \\
Full scale & 0.74 & 0.81 \\
\hline
\end{tabular}

Table 3 Entry-level of both experimental and control groups in students' scores on skills, participation, performance, emotional, and overall score for the pre-test "students' engagement"

\begin{tabular}{llllll}
\hline Engagement factor & Group & No & Arith Mean & Std. D & T "Value" \\
\hline Skills & Experiment & 60 & 21.07 & 1.89 & 0.464 \\
& Control & 58 & 24.25 & 1.72 & \\
Participation/Interaction & Experiment & 60 & 13.57 & 1.47 & 0.514 \\
& Control & 58 & 11.34 & 1.31 & \\
Performance & Experiment & 60 & 12.70 & 1.20 & 0.321 \\
& Control & 58 & 13.43 & 1.11 & \multirow{2}{*}{0.397} \\
Emotional & Experiment & 60 & 11.23 & 1.45 & \\
\multirow{2}{*}{ Whole engagement scale } & Control & 58 & 12.62 & 1.52 & \multirow{2}{*}{0.632} \\
& Experiment & 60 & 26.76 & 1.84 & \\
\hline
\end{tabular}

measure students' engagement, and to suggest what they deem appropriate in terms of modifications.

\section{Research procedures}

To calculate the homogeneity and group equivalence between both groups, the validity of the first hypothesis was examined which stated "There is no statistically significant difference between the students' mean scores of the experimental group that exposed to the adaptive e-learning environment and the scores of the control group that was exposed to the conventional e-learning environment in pre-application of students' engagement scale", the author applied the engagement scale to both groups beforehand, and the scores of the pre-application were examined to verify the equivalence of the two groups (experimental and control) in terms of students' engagement.

The t-test of independent samples was calculated for the engagement scale to confirm the homogeneity of the two classes before the experiment. The $t$-values were not significant at the level of significance $=0.05$, meaning that the two groups were homogeneous in terms of students' engagement scale before the experiment.

Since there was no significant difference in the mean scores of both groups $(p>0.05)$, the findings presented in Table 3 showed that there was no significant difference between both experimental and control groups in engagement as a whole, and each student engagement factor separately. The findings showed that the two classes were similar before start of research experiment. 


\section{Learner content path in adaptive e-learning environment}

The previous well-designed processes are the foundation for adaptation in e-learning environments. There are identified entries for accommodating materials, including classification depending on learning style.: kinesthetic, auditory, visual, and R/W. The present study covered the 1st semester during the 2019/2020 academic year. The course was divided into modules that concentrated on various topics; eleven of the modules included the adaptive learning exercise. The exercises and quizzes were assigned to specific textbook modules. To reduce irrelevant variation, all objects of the course covered the same content, had equal learning results, and were taught by the same instructor.

The experimental group-in which students were asked to bring smartphoneswas taught, where the how-to adaptive learning application for adaptive learning was downloaded, and a special account was created for each student, followed by access to the channel designed by the through the application, and the students were provided with instructions and training on how entering application with the appropriate default element of the developed learning objects, while the control group used the variety of instructional materials in the same course for the students.

In this adaptive e-course, students in the experimental group are presented with a questionnaire asked to answer that questions via a developed mobile App. They are provided with four choices. Students are allowed to answer the questions. The correct answer is shown in the students' responses to the results, but the learning module is marked as incomplete. If a student chooses to respond to a question, the correct answer is found immediately, regardless of the student's reaction.

Figure 8 illustrates a visual example from learning styles identification through responding VARK Questionnaire. The learning process experienced by the students in this adaptive Learning environment is as shown in Fig. 4. Students opened the adaptive course link by tapping the following app "https://play.google.com/store/apps/ details?id=com.pointability.vark," which displayed the appropriate positioning of both the learning skills course and the current status of students. It directed students to the learning skills that they are interested in learning more. Once students reached a specific situation in the e-learning environment, they could access relevant digital instructional materials. Students were then able to progress through the various styles offered by the proposed method, giving them greater flexibility in their learning pace.

The "flowchart" diagram below illustrates the learner's path in an adaptive e-learning environment, depending on the (VARK) learning styles (visual, auditory, kinesthetic, reading/writing) (Fig. 9).

According to the previous design model of the adaptive framework, the students responded "Learning Styles" questionnaire. Based on each student's results, the orientation of students will direct to each of "Visual", "Aural", "Read-Write", and "Kinesthetic". The student took at the beginning the engagement scale online according to their own pace. When ready, they responded "engagement scale".

Based on the results, the system produced an individualized learning plan to fill in the gap based on the VARK questionnaire's first results. The learner model represents important learner characteristics such as personal information, knowledge level, and learning preferences. Pre and post measurements were performed for both 


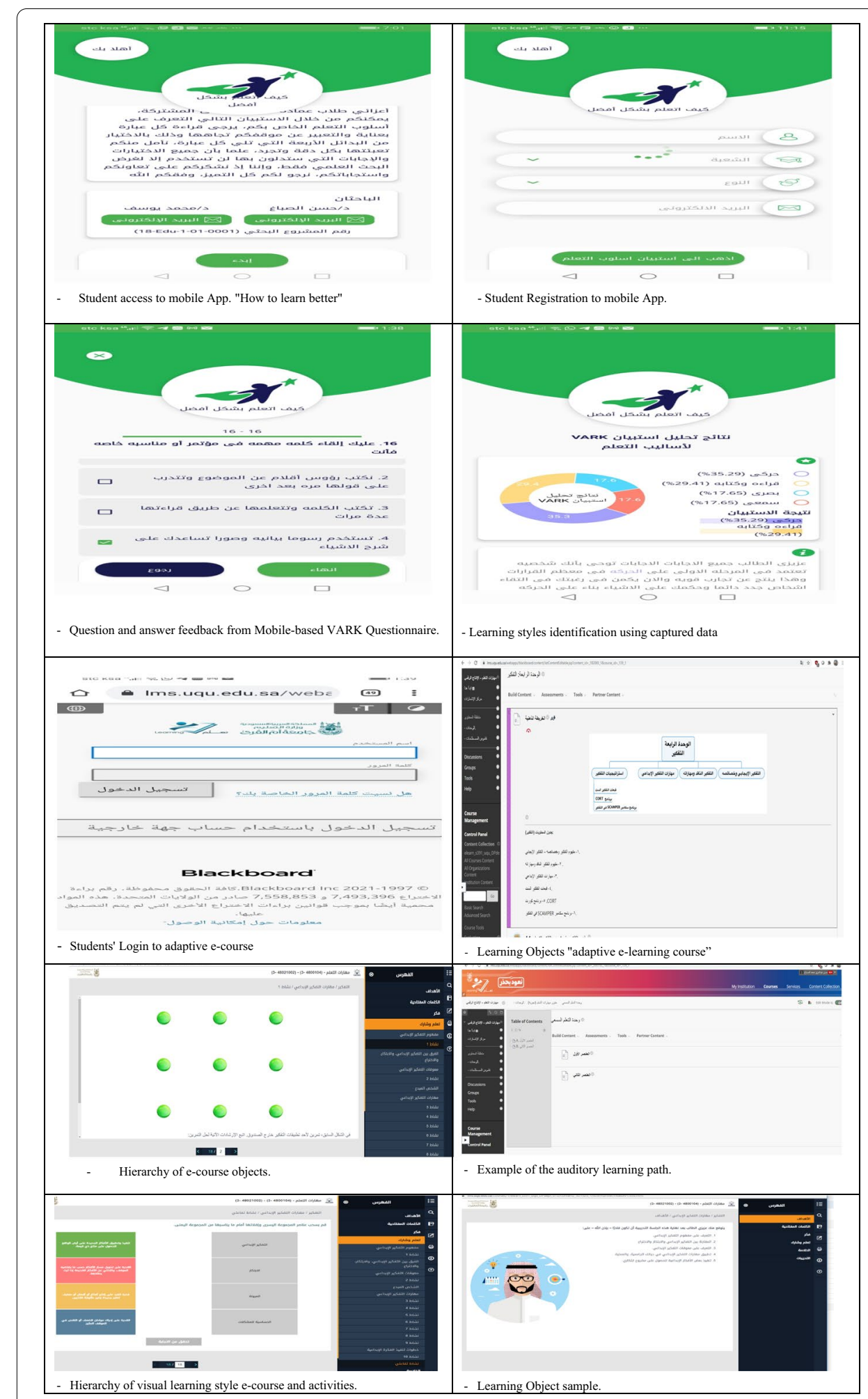

Fig. 8 Visual example from "learning of the learning styles" identification and adaptive e-learning course process 


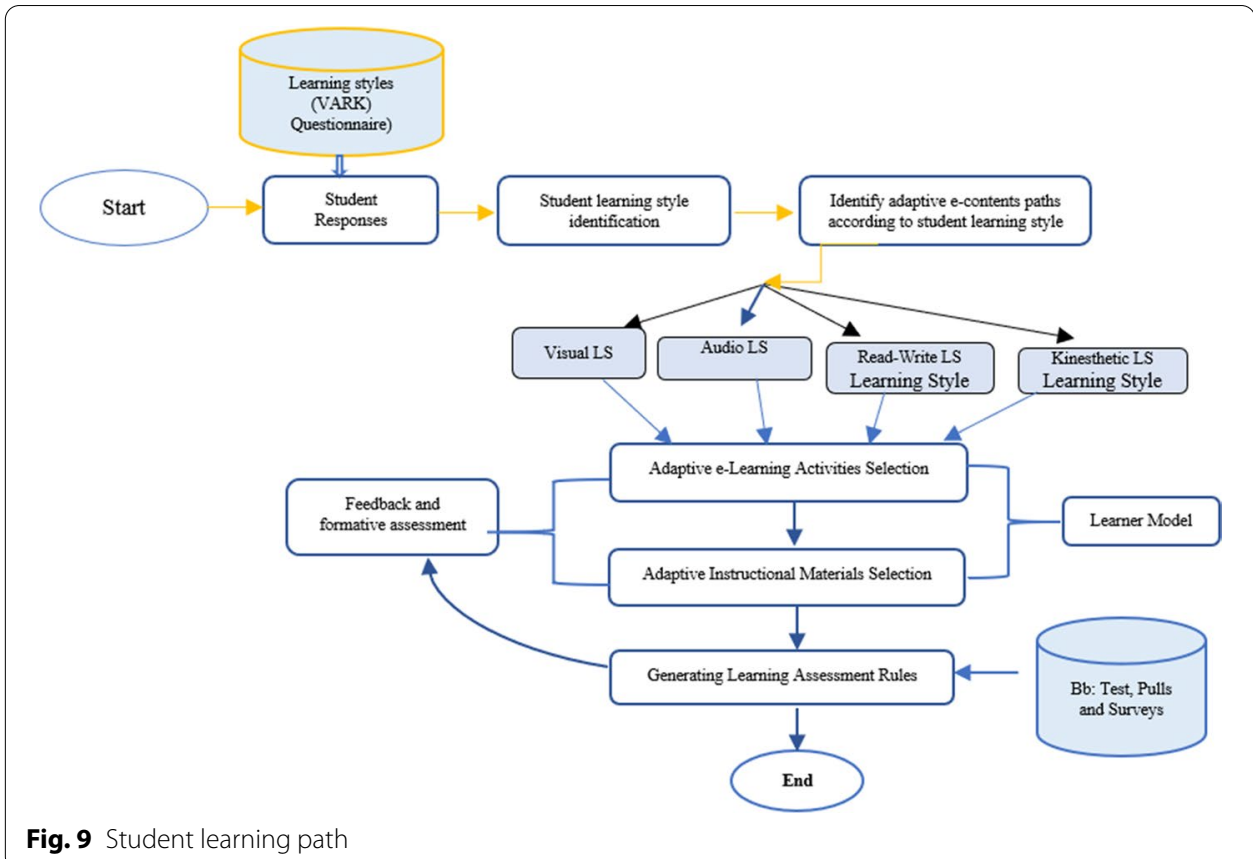

experimental and control groups. The experimental group was exposed only to treatment (using the adaptive learning environment).

\section{Findings}

To address the second question, which states: "What is the impact "effect" of adaptive e-learning based on (VARK) learning styles on development students' engagement (skills, participation/interaction, performance, emotional) in comparison with conventional e-learning?

The validity of the second hypothesis of the research hypothesis was tested, which states "There is a statistically significant difference at the level of $(0.05)$ between the students' mean scores of the experimental group (adaptive e-learning) and the scores of the control group (conventional e-learning) in post-application of students' engagement factors in favor of the experimental group". To test the hypothesis, the arithmetic means, standard deviations, and "T"-test values were calculated for the results of the two research groups in the application of engagement scale factors".

Table 4. indicates that students in the experimental group had significantly higher mean of engagement post-test (engagement factors items) scores than students in the control group $(p<0.05)$.

The experimental research was performed to evaluate the impact of the proposed adaptive e-learning. Independent sample t-tests were used to measure the previous behavioral engagement of the two groups related to topic of this research. Subsequently, the findings stated that the experimental group students had higher learning achievement than those who were taught using the conventional e-learning approach.

To verify the effect size of the independent variable in terms of the dependent variable, Cohen (d) was used to investigate that adaptive learning can significantly students' engagement. According to Cohen (1992), ES of 0.20 is small, 0.50 is medium, and 0.80 is 
Table 4 Descriptive data and independent sample t-tests of the pre-test results

\begin{tabular}{lllllll}
\hline Engagement factor & Learning group & No & Mean & Std. D & t value & $p$ \\
\hline Skills & Experimental group & 60 & 34.81 & 1.34 & 4.086 & $0.001^{*}$ \\
& Control group & 58 & 23.34 & 1.79 & & \\
Participation/Interaction & Experimental group & 60 & 21.05 & 1.09 & 2.210 & $0.002^{*}$ \\
& Control group & 58 & 13.26 & 1.43 & & \\
Performance & Experimental group & 60 & 25.86 & 1.47 & 2.071 & $0.003^{*}$ \\
Emotional & Control group & 58 & 14.60 & 1.35 & & \\
Average score & Experimental group & 60 & 24.93 & 1.84 & 2.909 & $0.001^{*}$ \\
& Control group & 58 & 13.07 & 2.03 & & \\
& Experimental group & 60 & 38.87 & 1.80 & 4.738 & $0.003^{*}$ \\
& Control group & 58 & 26.13 & 2.17 & & \\
\hline
\end{tabular}

${ }^{*} p<0.05,{ }^{*}$ Significant at 0.05 level

high. In the post-test of the student engagement scale, however, the effect size between students' scores in the experimental and control groups was calculated using ( $\mathrm{d}$ and r) using means and standard deviations. Cohen's $d=0.826$, and Effect-size $r=0.401$, according to the findings. The ES of 0.824 means that the treated group's mean is in the 79th percentile of the control group (Large effect). Effect sizes can also be described as the average percentile rank of the average treated learner compared to the average untreated learner in general. The mean of the treated group is at the 50th percentile of the untreated group, indicating an ES of 0.0. The mean of the treated group is at the 79th percentile of the untreated group, with an ES of 0.8. The results showed that the dependent variable was strongly influenced in the four behavioral engagement factors: skills: performance, participation/interaction, and emotional, based on the fact that effect size is a significant factor in determining the research's strength.

\section{Discussions and limitations}

This section discusses the impact of an adaptive e-learning environment on student engagement development. This paper aimed to design an adaptive e-learning environment based on learning style parameters. The findings revealed that factors correlated to student engagement in e-learning: skills, participation/interaction, performance, and emotional. The engagement factors are significant because they affect learning outcomes (Nkomo et al., 2021). Every factor's items correlate to cognitive process-related activities. The participation/interaction factor, for example, referred to, interactions with the content, peers, and instructors. As a result, student engagement in e-learning can be predicted by interactions with content, peers, and instructors. The results are in line with previous research, which found that customized learning materials are important for increasing students' engagement. Adaptive e-learning based on learning styles sets a strong emphasis on behavioral engagement, in which students manage their learning while actively participating in online classes to adapt instruction according to each learning style. This leads to improved learning outcomes (Al-Chalabi \& Hussein, 2020; Chun-Hui et al., 2017; Hussein \& Al-Chalabi, 2020; Pashler et al., 2008). The experimental findings of this research showed that students who learned through adaptive eLearning based on learning styles learned more; as learning styles are reflected in this research as one of the generally assumed concerns as a reference for adapting e-content path. Students in the experimental group reported that the adaptive eLearning environment was 
very interesting and able to attract their attention. Those students also indicated that the adaptive eLearning environment was particularly useful because it provided opportunities for them to recall the learning content, thus enhancing their overall learning impression. This may explain why students in the experimental group performed well in class and showed more enthusiasm than students in the control group. This research compared an adaptive e-learning environment to a conventional e-learning approach toward engagement in a learning skills course through instructional content delivery and assessment. It can also be noticed that the experimental group had higher participation than the control group, indicating that BB activities were better adapted to the students' learning styles. Previous studies have agreed on the effectiveness of adaptive learning; it provides students with quality opportunity that is adapted to their learning styles, and preferences (Alshammari, 2016; Hussein \& Al-Chalabi, 2020; Roy \& Roy, 2011; Surjono, 2014). However, it should be noted that this study is restricted to one aspect of content adaptation and its factors, which is learning materials adapting based on learning styles. Other considerations include content-dependent adaptation. These findings are consistent with other studies, such as (Alshammari \& Qtaish, 2019; Chun-Hui et al., 2017), which have revealed the effectiveness of the adaptive e-learning environment. This research differs from others in that it reflects on the Umm Al-Qura University as a case study, VARK Learning styles selection, engagement factors, and the closed learning management framework (BB).

The findings of the study revealed that adaptive content has a positive impact on adaptive individuals' achievement and student engagement, based on their learning styles (kinesthetic; auditory; visual; read/write). Several factors have contributed to this: The design of adaptive e-content for learning skills depended on introducing an ideal learning environment for learners, and providing support for learning adaptation according to the learning style, encouraging them to learn directly, achieving knowledge building, and be enjoyable in the learning process. Ali et al. (2019) confirmed that, indicating that education is adapted according to each individual's learning style, needs, and characteristics. Adaptive e-content design that allows different learners to think about knowledge by presenting information and skills in a logical sequence based on the adaptive e-learning framework, taking into account its capabilities as well as the diversity of its sources across the web, and these are consistent with the findings of (Alshammari \& Qtaish, 2019).

Accordingly, the previous results are due to the following: good design of the adaptive e-learning environment in light of the learning style and educational preferences according to its instructional design (ID) standards, and the provision of adaptive content that suits the learners' needs, characteristics, and learning style, in addition to the diversity of course content elements (texts, static images, animations, and video), variety of tests and activities, diversity of methods of reinforcement, return and support from the instructor and peers according to the learning style, as well as it allows ease of use, contains multiple and varied learning sources, and allows referring to the same point when leaving the environment.

Several studies have shown that using adaptive eLearning technologies allows students to improve their learning knowledge and further enhance their engagement in issues such as "skills, performance, interaction, and emotional" (Ali et al., 2019; Graf \& 
Kinshuk, 2007; Murray \& Pérez, 2015); nevertheless, Murray and Pérez (2015) revealed that adaptive learning environments have a limited impact on learning outcome.

The restricted empirical findings on the efficacy of adapting teaching to learning style are mixed. (Chun-Hui et al., 2017) demonstrated that adaptive eLearning technologies can be beneficial to students' learning and development. According to these findings, adaptive eLearning can be considered a valuable method for learning because it can attract students' attention and promote their participation in educational activities. (Ali et al., 2019); however, only a few recent studies have focused on how adaptive eLearning based on learning styles fits in diverse cultural programs. (Benhamdi et al., 2017; Pashler et al., 2008).

The experimental results revealed that the proposed environment significantly increased students' learning achievements as compared to the conventional e-learning classroom (without adaptive technology). This means that the proposed environment's adaptation could increase students' engagement in the learning process. There is also evidence that an adaptive environment positively impacts other aspects of quality such as student engagement (Murray \& Pérez, 2015).

\section{Conclusions and implications}

Although this field of research has stimulated many interests in recent years, there are still some unanswered questions. Some research gaps are established and filled in this study by developing an active adaptive e-learning environment that has been shown to increase student engagement. This study aimed to design an adaptive e-learning environment for performing interactive learning activities in a learning skills course. The main findings of this study revealed a significant difference in learning outcomes as well as positive results for adaptive e-learning students, indicating that it may be a helpful learning method for higher education. It also contributed to the current adaptive e-learning literature. The findings revealed that adaptive e-learning based on learning styles could help students stay engaged. Consequently, adaptive e-learning based on learning styles increased student engagement significantly. According to research, each student's learning style is unique, and they prefer to use different types of instructional materials and activities. Furthermore, students' preferences have an impact on the effectiveness of learning. As a result, the most effective learning environment should adjust its output to the needs of the students. The development of high-quality instructional materials and activities that are adapted to students' learning styles will help them participate and be more motivated. In conclusion, learning styles are a good starting point for creating instructional materials based on learning theories.

This study's results have important educational implications for future studies on the effect of adaptive e-learning on student interaction. First, the findings may provide data to support the development and improvement of adaptive environments used in blended learning. Second, the results emphasize the need for more quasi-experimental and descriptive research to better understand the benefits and challenges of incorporating adaptive e-learning in higher education institutions. Third, the results of this study indicate that using an adaptive model in an adaptive e-learning environment will encourage, motivate, engage, and activate students' active learning, as well as facilitate their knowledge construction, rather than simply taking in information passively. Fourth, new 
research is needed to design effective environments in which adaptive learning can be used in higher education institutions to increase academic performance and motivation in the learning process. Finally, the study shows that adaptive e-learning allows students to learn individually, which improves their learning and knowledge of course content, such as increasing their knowledge of learning skills course topics beyond what they can learn in a conventional e-learning classroom.

\section{Contribution to research}

The study is intended to provide empirical evidence of adaptive e-learning on student engagement factors. This research, on the other hand, has practical implications for higher education stakeholders, as it is intended to provide university faculty members with learning approaches that will improve student engagement. It is also expected to offer faculty a framework for designing personalized learning environments based on learning styles in various learning situations and designing more adaptive e-learning environments.

\section{Research implication}

Students with their preferred learning styles are more likely to enjoy learning if they are provided with a variety of instructional materials such as references, interactive media, videos, podcasts, storytelling, simulation, animation, problem-solving, games, and accessible educational tools in an e-learning environment. Also, different learning strategies can be accommodated. Other researchers would be able to conduct future studies on the use of the "adaptive e-learning" approach throughout the instructional process, at different phases of learning, and in various e-courses as a result of the current study. Meanwhile, the proposed environment's positive impact on student engagement gained considerable interest for future educational applications. Further research on learning styles in different university colleges could contribute to a foundation for designing adaptive e-courses based on students' learning styles and directing more future research on learning styles.

Implications for practice or policy:

- Adaptive e-learning focused on learning styles would help students become more engaged.

- Proving the efficacy of an adaptive e-learning environment via comparison with conventional e-learning.

\footnotetext{
Author information

Hassan A. El-Sabagh is an assistant professor in the E-Learning Deanship and head of the Instructional Programs Department, Umm Al-Qura University, Saudi Arabia, where he has worked since 2012. He has extensive experience in the field of e-learning and educational technologies, having served primarily at the Educational Technology Department of the Faculty of Specific Education, Mansoura University, Egypt since 1997. In 2011, he earned a Ph.D. in Educational Technology from Dresden University of Technology, Germany. He has over 14 papers published in international journals/conference proceedings, as well as serving as a peer reviewer in several international journals. His current research interests include eLearning Environments Design, Online Learning; LMS-based Interactive Tools, Augmented Reality, Design Personalized \& Adaptive Learning Environments, and Digital Education, Quality \& Online Courses Design, and Security issues of eLearning Environments. (E-mail: haelsabagh@uqu.edu.sa; haelsabagh@mans.edu.eg).
} 


\section{Acknowledgements}

The author would like to thank the Deanship of Scientific Research at Umm Al-Qura University for the continuous support. This work was supported financially by the Deanship of Scientific Research at Umm Al-Qura University to Dr:: Hassan Abd El-Aziz El-Sabagh. (Grant Code: 18-EDU-1-01-0001).

\section{Author contributions}

The author read and approved the final manuscript.

\section{Availability of data and materials}

The author confirms that the data supporting the findings of this study are based on the research tools which were prepared and explained by the author and available on the links stated in the research instruments sub-section. The data analysis that supports the findings of this study is available on request from the corresponding author.

\section{Declarations}

\section{Competing interests}

The author declares that there is no conflict of interest

\section{Author details}

'E-Learning Deanship, Umm Al-Qura University, Mecca, Saudi Arabia. ${ }^{2}$ Faculty of Specific Education, Mansoura University, Mansoura, Egypt.

Received: 24 May 2021 Accepted: 19 July 2021

Published online: 01 October 2021

\section{References}

Akbulut, Y., \& Cardak, C. (2012). Adaptive educational hypermedia accommodating learning styles: A content analysis of publications from 2000 to 2011. Computers \& Education. https://doi.org/10.1016/j.compedu.2011.10.008.

Al-Chalabi, H., \& Hussein, A. (2020). Analysis \& implementation of personalization parameters in the development of computer-based adaptive learning environment. SAR Journal Science and Research., 3(1), 3-9. https://doi.org/10. 18421//SAR31-01.

Aldosari, M., Aljabaa, A., Al-Sehaibany, F., \& Albarakati, S. (2018). Learning style preferences of dental students at a single institution in Riyadh Saudi Arabia, evaluated using the VARK questionnaire. Advances in Medical Education and Practice. https://doi.org/10.2147/AMEP.S157686.

Ali, N., Eassa, F., \& Hamed, E. (2019). Personalized Learning Style for Adaptive E-Learning System, International Journal of Advanced Trends in Computer Science and Engineering. 223-230. Retrieved June 26, 2020 from http://www.warse.org/ IJATCSE/static/pdf/file/ijatcse4181.12019.pdf.

Alshammari, M., \& Qtaish, A. (2019). Effective adaptive e-learning systems according to learning style and knowledge level. JITE Research, 18, 529-547. https://doi.org/10.28945/4459.

Alshammari, M. (2016). Adaptation based on learning style and knowledge level in e-learning systems, Ph.D. thesis, University of Birmingham. Retrieved April 18, 2019 from http://etheses.bham.ac.uk//id/eprint/6702/.

Alshammari, M., Anane, R., \& Hendley, R. (2015). Design and Usability Evaluation of Adaptive E-learning Systems based on Learner Knowledge and Learning Style. Human-Computer Interaction Conference-INTERACT, Vol. (9297), (pp. 157-186). https://doi.org/10.1007/978-3-319-22668-2_45.

Alzain, A., Clack, S., Jwaid, A., \& Ireson, G. (2018a). Adaptive education based on learning styles: Are learning style instruments precise enough. International Journal of Emerging Technologies in Learning (JJET), 13(9), 41-52. https://doi.org/ 10.3991/ijet.v13i09.8554.

Alzain, A., Clark, S., Ireson, G., \& Jwaid, A. (2018b). Learning personalization based on learning style instruments. Advances in Science Technology and Engineering Systems Journal. https://doi.org/10.25046/aj030315.

Atherton, M., Shah, M., Vazquez, J., Griffiths, Z., Jackson, B., \& Burgess, C. (2017). Using learning analytics to assess student engagement and academic outcomes in open access enabling programs". Journal of Open, Distance and e-Learning, 32(2), 119-136.

Barkley, E., \& Major, C. (2020). Student engagement techniques: A handbook for college faculty. Jossey-Bass . 10:047028191X.

Becker, K., Kehoe, J., \& Tennent, B. (2007). Impact of personalized learning styles on online delivery and assessment. Campus-Wide Information Systems. https://doi.org/10.1108/10650740710742718.

Behaz, A., \& Djoudi, M. (2012). Adaptation of learning resources based on the MBTI theory of psychological types. IJCSI International Journal of Computer Science, 9(2), 135-141.

Beldagli, B., \& Adiguzel, T. (2010). Illustrating an ideal adaptive e-learning: A conceptual framework. Procedia - Social and Behavioral Sciences, 2, 5755-5761. https://doi.org/10.1016/j.sbspro.2010.03.939.

Benhamdi, S., Babouri, A., \& Chiky, R. (2017). Personalized recommender system for e-Learning environment. Education and Information Technologies, 22, 1455-1477. https://doi.org/10.1007/s10639-016-9504-y.

Chen, P., Lambert, A., \& Guidry, K. (2010). Engaging online learners: The impact of Web-based learning technology on college student engagement. Computers \& Education, 54, 1222-1232.

Chun-Hui, Wu., Chen, Y.-S., \& Chen, T. C. (2017). An adaptive e-learning system for enhancing learning performance: based on dynamic scaffolding theory. Eurasia Journal of Mathematics, Science and Technology Education. https://doi.org/10. 12973/ejmste/81061.

Cletus, D., \& Eneluwe, D. (2020). The impact of learning style on student performance: mediate by personality. International Journal of Education, Learning and Training. https://doi.org/10.24924/ijelt/2019.11/v4.iss2/22.47Desmond. 
Cohen, J. (1992). Statistical power analysis. Current Directions in Psychological Science., 1(3), 98-101. https://doi.org/10. 1111/1467-8721.ep10768783.

Daines, J., Troka, T. and Santiago, J. (2016). Improving performance in trigonometry and pre-calculus by incorporating adaptive learning technology into blended models on campus. https://doi.org/10.18260/p.25624.

DeCapua, A. \& Marshall, H. (2015). Implementing a Mutually Adaptive Learning Paradigm in a Community-Based Adult ESL Literacy Class. In M. Santos \& A. Whiteside (Eds.). Low Educated Second Language and Literacy Acquisition. Proceedings of the Ninth Symposium (pps. 151-171). Retrieved Nov. 14, 2020 from https://www.researchgate.net/publication/ 301355138_Implementing_a_Mutually_Adaptive_Learning_Paradigm_in_a_Community-Based_Adult_ESL_Liter acy_Class.

Dixson, M. (2015). Measuring student engagement in the online course: The online student engagement scale (OSE). Online Learning. https://doi.org/10.24059/olj.v19i4.561.

Dominic, M., Xavier, B., \& Francis, S. (2015). A Framework to Formulate Adaptivity for Adaptive e-Learning System Using User Response Theory. International Journal of Modern Education and Computer Science, 7, 23. https://doi.org/10. 5815/ijmecs.2015.01.04.

El Bachari, E., Abdelwahed, E., \& M., El. . (2011). E-Learning personalization based on Dynamic learners' preference. International Journal of Computer Science and Information Technology., 3, 200-216. https://doi.org/10.5121/ijcsit.2011.3314.

El-Sabagh, H. A., \& Hamed, E. (2020). The Relationship between Learning-Styles and Learning Motivation of Students at Umm Al-Qura University. Egyptian Association for Educational Computer Journal. https://doi.org/10.21608/EAEC.2020. 25868.1015 ISSN-Online: 2682-2601.

Ennouamani, S., \& Mahani, Z. (2017). An overview of adaptive e-learning systems. Eighth International ConfeRence on Intelligent Computing and Information Systems (ICICIS). https://doi.org/10.1109/INTELCIS.2017.8260060.

Evans, S., Steele, J., Robertson, S., \& Dyer, D. (2017). Personalizing post titles in the online classroom: A best practice? Journal of Educators Online, 14(2), 46-54.

Fleming, N., \& Baume, D. (2006). Learning styles again: VARKing up the Right Tree! Educational Developments, 7, 4-7.

Franzoni, A., \& Assar, S. (2009). Student learning style adaptation method based on teaching strategies and electronic media. Journal of Educational Technology \& Society, 12(4), 15-29. Retrieved March 21, 2020, from http://www.jstor. org/stable/jeductechsoci.12.4.15.

Fredricks, J., Blumenfeld, P., \& Paris, A. (2004). School Engagement: Potential of the Concept. State of the Evidence: Review of Educational Research. https://doi.org/10.3102/00346543074001059.

Gaytan, J., \& McEwen, M. (2007). Effective Online Instructional and Assessment Strategies. American Journal of Distance Education, 21(3), 117-132. https://doi.org/10.1080/08923640701341653.

Graf, S. \& Kinshuk. K. (2007). Providing Adaptive Courses in Learning Management Systems with respect to Learning Styles. Proceeding of the World Conference on eLearning in Corporate. Government. Healthcare. and Higher Education (2576-2583). Association for the Advancement of Computing in Education (AACE). Retrieved January 18, 2020 from https://www.learntechlib.org/primary/p/26739/. ISBN 978-1-880094-63-1.

Guo, P., Kim, V., \& Rubin, R. (2014). How video production affects student engagement: an empirical study of MOOC videos. Proceedings of First ACM Conference on Learning @ Scale Confernce. March 2014, (pp. 41-50). https://doi.org/10. $1145 / 2556325.2566239$

Hinton, P. R., Brownlow, C., McMurray, I., \& Cozens, B. (2014). SPSS Explained (2nd ed., pp. 339-354). Routledge Taylor \& Francis Group.

Hong, S. (2009). Developing competency model of learners in distance universities. Journal of Educational Technology., 25 , 157-186.

Hussain, I. (2017). Pedagogical implications of VARK model of learning. Journal of Literature, Languages and Linguistics, 38, 33-37.

Hussain, M., Zhu, W., Zhang, W., \& Abidi, S. (2018). Student engagement predictions in an e-learning system and their impact on student course assessment scores. Computational Intelligence, and Neuroscience. https://doi.org/10.1155/ 2018/6347186.

Hussein, A., \& Al-Chalabi, H. (2020). Pedagogical Agents in an Adaptive E-learning System. SAR Journal of Science and Research., 3, 24-30. https://doi.org/10.18421/SAR31-04.

Jaleel, S., \& Thomas, A. (2019). Learning styles theories and implications for teaching learning. Horizon Research Publishing. 978-1-943484-25-6.

Johnson, M. (2009). Evaluation of Learning Style for First-Year Medical Students. Int J Schol Teach Learn. https://doi.org/10. 20429/ijsotl.2009.030120.

Jonassen, D. H., \& Grabowski, B. L. (2012). Handbook of individual differences, learning, and instruction. Routledge. https:// doi.org/10.1016/0022-4405(95)00013-C.

Klasnja-Milicevic, A., Vesin, B., Ivanovic, M., \& Budimac, Z. (2011). E-Learning personalization based on hybrid recommendation strategy and learning style identification. Computers \& Education, 56(3), 885-899. https://doi.org/10.1016/j. compedu.2010.11.001.

Kolekar, S. V., Pai, R. M., \& Manohara Pai, M. M. (2017). Prediction of learner's profile based on learning styles in adaptive e-learning system. International Journal of Emerging Technologies in Learning, 12(6), 31-51. https://doi.org/10.3991/ ijet.v12i06.6579.

Lee, J., \& Kim, D. (2012). Adaptive learning system applied bruner'EIS theory. International Conference on Future Computer Supported Education, IERI Procedia, 2, 794-801. https://doi.org/10.1016/j.ieri.2012.06.173.

Lee, J., Song, H.-D., \& Hong, A. (2019). Exploring factors, and indicators for measuring students' sustainable engagement in e-learning. Sustainability, 11, 985. https://doi.org/10.3390/su11040985.

Leung, A., McGregor, M., Sabiston, D., \& Vriliotis, S. (2014). VARK learning styles and student performance in principles of Micro-vs. Macro-Economics. Journal of Economics and Economic Education Research, 15(3), 113.

Lévy, P. \& Wakabayashi, N. (2008). User's appreciation of engagement in service design: The case of food service design. Proceedings of International Service Innovation Design Conference 2008 - ISIDC08. Busan, Korea. Retrieved October 28, 2019 from https://www.researchgate.net/publication/230584075. 
Liang, J. S. (2012). The effects of learning styles and perceptions on application of interactive learning guides for webbased. Proceedings of Australasian Association for Engineering Education Conference AAEE. Melbourne, Australia. Retrieved October 22, 2019 from https://aaee.net.au/wpcontent/uploads/2018/10/AAEE2012-Liang.-Learning_ styles_and_perceptions_effects_on_interactive_learning_guide_application.pdf.

Mahnane, L., Laskri, M. T., \& Trigano, P. (2013). A model of adaptive e-learning hypermedia system based on thinking and learning styles. International Journal of Multimedia and Ubiquitous Engineering, 8(3), 339-350.

Markey, M. K. \& Schmit, K, J. (2008). Relationship between learning style Preference and instructional technology usage. Proceedings of American Society for Engineering Education Annual Conference \& Expodition. Pittsburgh, Pennsylvania. Retrieved March 15, 2020 from https://peer.asee.org/3173.

McMillan, J., \& Schumacher, S. (2006). Research in education: Evidence-based inquiry. Pearson.

Murphy, R., Gray, S., Straja, S., \& Bogert, M. (2004). Student learning preferences and teaching implications: Educational methodologies. Journal of Dental Education, 68(8), 859-866.

Murray, M., \& Pérez, J. (2015). Informing and performing: A study comparing adaptive learning to traditional learning. Informing Science. The International Journal of an Emerging Transdiscipline, 18, 111-125. Retrieved Febrauary 4, 2021 from http://www.inform.nu/Articles/Nol18/ISJv18p111-125Murray1572.pdf.

Mutahi, J., Kinai, A. , Bore, N. , Diriye, A. and Weldemariam, K. (2017). Studying engagement and performance with learning technology in an African classroom, Proceedings of Seventh International Learning Analytics \& Knowledge Conference, (pp. 148-152), Canada: Vancouver.

Nainie, Z., Siraj, S., Abuzaiad, R. A., \& Shagholi, R. (2010). Hypothesized learners'technology preferences based on learning styles dimensions. The Turkish Online Journal of Educational Technology, 9(4), 83-93.

Naqeeb, H. (2011). Learning Styles as Perceived by Learners of English as a Foreign Language in the English Language Center of The Arab American University—Jenin. Palestine. an Najah Journal of Research, 25, 2232.

Nkomo, L. M., Daniel, B. K., \& Butson, R. J. (2021). Synthesis of student engagement with digital technologies: a systematic review of the literature. International Journal of Educational Technology in Higher Education. https://doi.org/10.1186/ s41239-021-00270-1.

Normadhi, N. B., Shuib, L., Nasir, H. N. M., Bimba, A., Idris, N., \& Balakrishnan, V. (2019). Identification of personal traits in adaptive learning environment: Systematic literature review. Computers \& Education, 130, 168-190. https://doi.org/ 10.1016/j.compedu.2018.11.005.

Nuankaew, P., Nuankaew, W., Phanniphong, K., Imwut, S., \& Bussaman, S. (2019). Students model in different learning styles of academic achievement at the University of Phayao, Thailand. International Journal of Emerging Technologies in Learning (iJET)., 14, 133. https://doi.org/10.3991/ijet.v14i12.10352.

Oxman, S. \& Wong, W. (2014). White Paper: Adaptive Learning Systems. DV X Innovations DeVry Education Group. Retrieved December 14, 2020 from shorturl.at/hnsS8.

Ozyurt, Ö., \& Ozyurt, H. (2015). Learning style-based individualized adaptive e-learning environments: Content analysis of the articles published from 2005 to 2014. Computers in Human Behavior, 52, 349-358. https://doi.org/10.1016/j.chb. 2015.06.020.

Pardo, A., Han, F., \& Ellis, R. (2016). Exploring the relation between self-regulation, online activities, and academic performance: a case study. Proceedings of Sixth International Conference on Learning Analytics \& Knowledge, (pp. 422-429). https://doi.org/10.1145/2883851.2883883.

Pashler, H., McDaniel, M., Rohrer, D., \& Bjork, R. (2008). Learning styles: concepts and evidence. Psychology Faculty Publications., 9(3), 105-119. https://doi.org/10.1111/j.1539-6053.2009.01038.x.

Qazdar, A., Cherkaoui, C., Er-Raha, B., \& Mammass, D. (2015). AeLF: Mixing adaptive learning system with learning management system. International Journal of Computer Applications., 119, 1-8. https://doi.org/10.5120/21140-4171.

Robinson, C., \& Hullinger, H. (2008). New benchmarks in higher education: Student engagement in online learning. Journal of Education for Business, 84, 101-109.

Rogers-Stacy, C., Weister, T., \& Lauer, S. (2017). Nonverbal immediacy behaviors and online student engagement: Bringing past instructional research into the present virtual classroom. Communication Education, 66(1), 37-53.

Roy, S., \& Roy, D. (2011). Adaptive e-learning system: a review. International Journal of Computer Trends and Technology (IJCTT), 1(1), 78-81. ISSN:2231-2803.

Shi, L., Cristea, A., Foss, J., Qudah, D., \& Qaffas, A. (2013). A social personalized adaptive e-learning environment: a case study in topolor. IADIS International Journal on WWW/Internet., 11, 13-34.

Shih, M., Feng, J., \&Tsai, C. (2008). Research and trends in the field of e-learning from 2001 to 2005: A content analysis of cognitive studies in selected journals. Computers \& Education, 51(2), 955-967. https://doi.org/10.1016/j.compedu. 2007.10.004.

Silva, A. (2020). Towards a Fuzzy Questionnaire of Felder and Solomon for determining learning styles without dichotomic in the answers. Journal of Learning Styles, 13(15), 146-166.

Staikopoulos, A., Keeffe, I., Yousuf, B. et al., (2015). Enhancing student engagement through personalized motivations. Proceedings of IEEE 15th International Conference on Advanced Learning Technologies, (pp. 340-344), Taiwan: Hualien. https://doi.org/10.1109/ICALT.2015.116.

Surjono, H. D. (2014). The evaluation of Moodle-based adaptive e-learning system. International Journal of Information and Education Technology, 4(1), 89-92. https://doi.org/10.7763/IJIET.2014.V4.375.

Truong, H. (2016). Integrating learning styles and adaptive e-learning system: current developments, problems, and opportunities. Computers in Human Behavior, 55(2016), 1185-1193. https://doi.org/10.1016/j.chb.2015.02.014.

Umm Al-Qura University Agency for Educational Affairs (2020). Common first-year Deanship, at Umm Al-Qura University. Retrieved February 3, 2020 fromhttps://uqu.edu.sa/en/pre-edu/70021.

Vassileva, D. (2012). Adaptive e-learning content design and delivery based on learning style and knowledge level. Serdica Journal of Computing, 6, 207-252.

Veiga, F., Robu, V., Appleton, J., Festas, I \& Galvao, D. (2014). Students'engagement in school: Analysis according to self-concept and grade level. Proceedings of EDULEARN14 Conference 7th-9th July 2014 (pp. 7476-7484). Barcelona, Spain. Available Online at: http://hdl.handle.net/10451/12044. 
Velázquez, A., \& Assar, S. (2009). Student learning styles adaptation method based on teaching strategies and electronic media. Educational Technology \& SocieTy., 12, 15-29.

Verdú, E., Regueras, L., \& De Castro, J. (2008). An analysis of the research on adaptive Learning: The next generation of e-learning. WSEAS Transactions on Information Science and Applications, 6(5), 859-868.

Willingham, D., Hughes, E., \& Dobolyi, D. (2015). The scientific status of learning styles theories. Teaching of Psychology., 42(3), 266-271. https://doi.org/10.1177/0098628315589505.

Yalcinalp \& Avcı. (2019). Creativity and emerging digital educational technologies: A systematic review. The Turkish Online Journal of Educational Technology, 18(3), 25-45.

Yang, J., Huang, R., \& Li, Y. (2013). Optimizing classroom environment to support technology enhanced learning. In A. Holzinger \& G. Pasi (Eds.), Human-computer interaction and knowledge discovery in complex (pp. 275-284). Berlin: Springer.

Zhang, H. (2017). Accommodating different learning styles in the teaching of economics: with emphasis on fleming and millsj's sensory-based learning style typology. Applied Economics and Finance, 4(1), 72-78.

\section{Publisher's Note}

Springer Nature remains neutral with regard to jurisdictional claims in published maps and institutional affiliations.

\section{Submit your manuscript to a SpringerOpen ${ }^{\circ}$} journal and benefit from:

Convenient online submission

- Rigorous peer review

- Open access: articles freely available online

- High visibility within the field

Retaining the copyright to your article

Submit your next manuscript at $\gg$ springeropen.com 